\title{
LA LECTURA COMO EJERCICIO MARGINAL EN LA NARRATIVA DE ROBERTO BOLAÑO
}

\author{
Felipe Adrián Ríos Baeza ${ }^{1}$
}

\section{Resumen/Abstract}

No todos los personajes del escritor chileno Roberto Bolaño escriben; pero, en cambio, todos parecen leer. En este ensayo se busca estudiar una constante en su obra: sus protagonistas acceden de manera fervorosa a la literatura en cárceles, en frentes de batalla, en farmacias, en puestos de comida exótica, en peluquerías, en playas y en talleres mecánicos. De esta manera, la literatura parece huir de los espacios tradicionales y de su ejercicio emisor-para instalarse en lugares marginales, fronterizos, y así poder sobrevivir. Además de ayudar a desacralizar la práctica literaria - otra constante en la obra de Bolaño-, esta situación resultará constitutiva, en tanto transfiguración de identidad, entre quienes se atreven a abrazar la práctica literaria cabalmente. La lectura, en sitios que no son los habituales, es asumida como un aliciente y un mecanismo tenue para que los personajes vayan accediendo a zonas donde toda seguridad y certeza se desmantela, en una línea epistemológica muy cercana a lo planteado por el postestructuralismo francés en torno al ejercicio de recepción textual.

Palabras clave: Roberto Bolaño, margen, lectura, espacio, teoría de la lectura

\section{THE READING AS A MARGINAL EXERCISE IN ROBERTO BOLAÑO'S NARRATIVE}

Not all the characters from Chilean writer Roberto Bolaño write, but, on the other hand, all of them seem to read. This essay tries to look for a constant in his work: his main characters have a zealous access to literature in jails, battle fronts, pharmacies, exotic food stands, barber shops, beaches and workshops. This way, literature seems to step away from the traditional spaces -as well as its original writing spaceto be situated in marginal and border spaces, so that it can survive. Besides helping stop the idolization of the literary practice (another constant in Bolaño's work), this situation will be part of its formation, when referring to the transfiguration of the identity, among those who dare to thoroughly embrace the literary practice. The reading, in spaces which are not the traditional ones, is assumed as an incentive and a soft mechanism for the characters to start gaining access to zones where all safety and certainty is dismantled in an epistemological line that lies very close to the French poststructuralism regarding the reception of a text.

Keywords: Roberto Bolaño, margin, reading, space, reading theory.

\footnotetext{
${ }^{1}$ Chileno, Universidad Anáhuac Querétaro. E-mail: felipe.rios.baeza@gmail.com
}

Recibido: 27 agosto 2018

Aceptado: 02 mayo 2019 


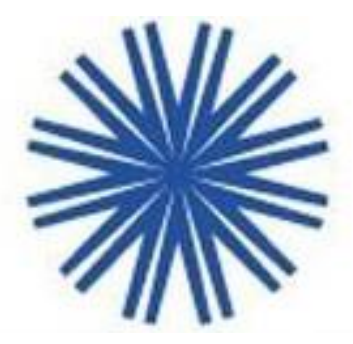

Desde hace dos décadas, la literatura de Roberto Bolaño (1953-2003) ha merecido una atención especial por parte de la crítica especializada. Muy tempranamente, los recopilatorios de Celina Manzoni (2002) y de Patricia Espinosa (2003) permitieron vislumbrar los focos de atención y las tendencias incipientes con las cuales sus libros serían observados. De esta manera, la irrupción del mal y de la ignominia, al momento de referir eventos históricos como la dictadura de Pinochet, en Chile, o el holocausto judío; el desorden y la parodia del canon literario hispanoamericano; el trabajo con la autoficción (visible en la figura de B y de Arturo Belano); y la posibilidad de estar delante de una literatura total, al evidenciar las corrientes explícitas y subterráneas entre sus libros, fueron temas que preocuparon con justeza a los primeros críticos serios de su obra.

No obstante, a partir de ciertos trabajos, como los de Alan Pauls (2008), Patricia Poblete Alday (2010), Myrna Solotorevsky (2012), y sobre todo Alberto del Pozo Martínez (2014), hay un señalamiento decisivo para comprender una arista evidente en sus textos: la presencia obsesiva de la literatura y de sus contornos, escriturales y lectores. Dicho reconocimiento no resulta original, en un comienzo los personajes más recordados del autor -Benno von Archimboldi, Cesárea Tinajero, los realvisceralistas, los escritores nazis de América, Sensini, el mismo Belano, etc.- proyectan en los relatos y novelas donde aparecen un fervor único por un proyecto estético ambicioso. Sin embargo, en 2008 Alan Pauls, acaso el primero, reconoció un asunto más complejo que el evidente juego metaficcional: “[N]i Belano, ni Ulises Lima, ni el joven García Madero -que prácticamente nadie, ninguno de los poetas que se multiplican en las páginas de Los detectives salvajes, escribe nada -nada, en todo caso, que nos sea dado a leer. Un libro inflamado, henchido, rebosante de poetas -y no hay Obra." (Pauls: 327).

Es algo que se ha comentado en otros lugares ${ }^{2}$ : los libros de Bolaño glosan, comentan, desmenuzan, analizan, ensalzan o rechazan referencias literarias (apócrifas o reales). Pero, ¿dónde se encuentra, realmente, situada la literatura?, ¿en qué lugar es posible evidenciar la obra concreta de Lima y Belano, de Archimboldi, de Henri Simone Leprince o Enrique Martín? Tomando como ejemplo Los detectives salvajes (1998), Pauls dice que Bolaño "hace brillar a la Obra por su ausencia; porque en el lugar central,

\footnotetext{
${ }^{2}$ Cf. Felipe Ríos Baeza, Roberto Bolaño: Una narrativa en el margen. Desestabilizaciones en el canon y la cultura. Valencia: Tirant Lo Blanch, 2013.
} 
en la médula del libro, allí donde deberíamos ver desplegarse las artes, el saber, la intuición, el don de lengua de los poetas [...], lo único que hay son ráfagas de aire, torbellinos hiperquinéticos, una especie de movimiento grupuscular continuo, una compulsión a respirar, a tragar aire, un gregarismo hiperventilado, un atletismo de pulmones rotos y músculos gastados, fugas hacia delante.” (Pauls: 327-328).

En este ensayo, y echando mano a algunos planteamientos de la teoría de la lectura, pero sobre todo a enfoques propios, proponemos perseguir la estela de esta literatura que se ha fugado hacia delante. La ausencia de una centralidad, en términos de la visibilidad de una obra, en la literatura de Bolaño es parte de su ambicioso proyecto narrativo, que reemplaza el gusto de escribir por una práctica apasionada de la lectura. Necesariamente, si la literatura ha escapado en estampida de los centros, debe encontrarse en los márgenes, en los bordes sociales, donde varios de sus personajes transitan y leen, peligrosamente. El propósito, pues, es ver cómo la presencia de lo literario, en estas fronteras, reconfigura sensibilidades y percepciones de sus personajes, y obliga a pensar, en términos críticos, que la posición de las actividades de leer y escribir en su propuesta es más compleja de lo que aparentemente le parecía a la crítica literaria inicial.

\section{Lecturas fecundando el margen}

El asunto puede evidenciarse desde su primera novela, Consejos de un discípulo de Morrison a un fanático de Joyce (1984) - escrita a dos manos con Antoni García Porta-, hasta obras póstumas, como los cuentos de El secreto del mal (2007) y la novela Los sinsabores del verdadero policía (2011). Belano, el otrora realvisceralista, acaba en una aldea en llamas mirando un libro de retratos de poetas franceses, en el relato «Fotos», de Putas asesinas; su amigo Ulises Lima, en Los detectives salvajes, pone en pausa el oficio de poeta para convertirse en un dealer, traficando marihuana desde Acapulco; Henri Simon Leprince, en el cuento homónimo incluido en Llamadas telefónicas (1997), escribe un largo poema de 600 versos donde descubre que no es un mal poeta, pero abandona la tentativa. Estos y otros ejemplos marcan la constante: en la obra de Bolaño, la literatura arrebata a determinados personajes, permite que se recreen en sus pormenores fascinantes, pero luego siguen camino hacia otros espacios y otras subjetividades. Así, es posible evidenciar que en su narrativa no se ficcionaliza tanto el ejercicio literario como la posibilidad de salir de él, ya sea negándose a seguir escribiendo (una opción bartleby, al decir de Enrique Vila-Matas), o bien estableciendo para la literatura otra epistemología, según los lugares donde se instale. 
Así, cuando Ángel Ros, protagonista de Consejos de un discípulo de Morrison a un fanático de Joyce, comienza a sentir los estragos del amorío desesperado que lo ata a Ana, su novia sudamericana, busca refugio en bares periféricos. En uno de esos sitios de ocio encuentra a un excéntrico grupo de hombres que, primero, muestran sus credenciales algo pendencieras para luego exhibir, sorprendentemente, las literarias:

No me sorprendí cuando el alto, que era quien llevaba la voz cantante, anunció, mientras esperábamos en la barra la llegada de unas tapas de anchoa, su oficio de poeta.

Lo demás fue rápido y verosímil:

- Yo también soy poeta — dijo el marica bajito.

-Y yo - dijo su amigo, un chico gallego de unos veinte años, moreno y de ojos verdes.

- Bueno, yo también he escrito poesía - anuncié, no muy seguro de que me fueran a creer.

Al final todos éramos escritores: el larguirucho había publicado con su dinero un par de libros, los otros eran inéditos y marginales, aunque al bajito le habían publicado un poema en Camp de l'Arpa, antigua época, y el gallego, para mi sorpresa y beneplácito general, había sido incluido en una muestra de poesía visual que en esos días se exhibía en la única galería de arte de La Mina o algo parecido [...].

— Siéntate — dijo el gallego- Estamos escribiendo un cadáver exquisito.

— iUn cadáver exquisito! ¡Sí, me gusta! — gritó el largo, como si despertara. (Bolaño, García Porta: 101-102)

Es significativo que en un espacio no tradicional para el encuentro artístico, una galería tan abigarrada de personajes tenga conocimiento de los mecanismos de creación de una vanguardia como la dadaísta ${ }^{3}$. Se recordará, primero, y confiando en la declaración de principios de Juan García Madero, en Los detectives salvajes, que el movimiento de vanguardia realvisceralista surgía también desde la marginalidad, desde las azoteas, desde las viviendas pobres, desde los habitáculos caóticos; y en segundo lugar, que la Escritura Bárbara, aquella práctica perpetrada en derruidos y minúsculos cuartos, y comandada por el portero Raoul Delorme en Estrella distante (1996), pretendía erigirse como la quintaesencia de la humanización libresca,

\footnotetext{
${ }^{3}$ Desde esta perspectiva, serían elocuentes las intenciones de Udo Berger en El Tercer Reich (2010) de convertirse en escritor, confesión otorgada en una playa fronteriza y dentro de una fortaleza creada por los patines que el Quemado le alquila a los veraneantes: «Ignoro qué impulso me hizo confesarle que pretendía ser escritor. El Quemado se giró y tras vacilar dijo que era una profesión interesante. Se lo hice repetir pues al principio creí malinterpretarlo.

- Pero no de novelas ni de obras de teatro-aclaré.

El Quemado entreabrió los labios y dijo algo que no pude escuchar.

- ¿Qué?

- ¿Poeta?

Debajo de sus cicatrices creí ver una especie de sonrisa monstruosa. Pensé que el sol me estaba atontando.

-No, no, por supuesto, poeta no.

Aclaré, ya que me había dado pie para ello, que yo no despreciaba en modo alguno la poesía. Hubiera podido recitar de memoria versos de Klopstock o de Schiller; pero escribir versos en estos tiempos, como no fueran para la amada, resultaba un tanto inútil, ¿no lo veía así?» (Bolaño, 2010: 79).
} 
un método irrespetuoso pero necesario para democratizar el ejercicio literario ${ }^{4}$. La relación, entonces, entre ars poética y espacio fronterizo parece clara: el anquilosamiento discursivo e ideológico de los espacios céntricos no permite que la literatura alcance empresas mayores, cuando la literatura, según deducciones de la propia narrativa de Bolaño, ha tenido una histórica voluntad de actualizarse e indefinirse, resignificarse e incluso abandonar a los personajes que mayormente siguen su estela.

Analizando un caso anterior al de Delorme, en Estrella distante, es posible apuntar un elemento interesante por parte de quienes escriben. Varios personajes de dicha novela, entre ellos Bibiano O'Ryan y el narrador Bolaño, toman contacto con Carlos Wieder pocos años antes del golpe militar chileno, cuando el futuro poeta feminicida se hacía llamar Alberto Ruiz-Tagle y frecuentaba con complacencia los talleres de poesía de Diego Soto y Juan Stein, en la Universidad de Concepción. Bolaño registra del siguiente modo el entorno particular donde tiene lugar el taller de Soto ${ }^{5}$ :

El taller de Soto estaba en la Facultad de Medicina, ignoro por qué razón, en un cuarto mal ventilado y mal amoblado, separado tan sólo por el pasillo del anfiteatro en donde los estudiantes despiezaban cadáveres en las clases de anatomía. El anfiteatro, por supuesto, olía a formol. El pasillo, en ocasiones, también olía a formol. Y algunas noches, pues el taller de Soto funcionaba todos los viernes de ocho a diez, aunque generalmente solía acabar pasadas las doce, el cuarto se

\footnotetext{
4 "Nacido en 1935, Raoul Delorme fue soldado y vendedor del mercado de abastos antes de encontrar una colocación fija (y más acorde con una ligera enfermedad en las vértebras contraída en la Legión) como portero de un edificio del centro de París. En 1968, mientras los estudiantes levantaban barricadas y los futuros novelistas de Francia rompían a ladrillazos las ventanas de sus Liceos o hacían el amor por primera vez, decidió fundar la secta o el movimiento de los Escritores Bárbaros. Así que, mientras unos intelectuales salían a tomar las calles, el antiguo legionario se encerró en su minúscula portería de la rue Des Eaux y comenzó a dar forma a su nueva literatura. El aprendizaje consistía en dos pasos aparentemente sencillos. El encierro y la lectura. Para el primer paso había que comprar víveres suficientes para una semana o ayunar. También era necesario, para evitar las visitas inoportunas, avisar que uno no estaba disponible para nadie o que salía de viaje por una semana o que había contraído una enfermedad contagiosa. El segundo paso era más complicado. Según Delorme, había que fundirse con las obras maestras. Esto se conseguía de una manera harto curiosa: defecando sobre las páginas de Stendhal, sonándose los mocos con las páginas de Víctor Hugo, masturbándose y desparramando el semen sobre las páginas de Gautier o Banville, vomitando sobre las páginas de Daudet, orinándose sobre las páginas de Lamartine, haciéndose cortes con hojas de afeitar y salpicando de sangre las páginas de Balzac o Maupassant, sometiendo, en fin, a los libros a un proceso de degradación que Delorme llamaba humanización. El resultado, tras una semana de ritual bárbaro, era un departamento o una habitación llena de libros destrozados, suciedad y mal olor en donde el aprendiz de literato boqueaba a sus anchas, desnudo o vestido con shorts, sucio y convulso como un recién nacido o más apropiadamente como el primer pez que decidió dar el salto y vivir fuera del agua. Según Delorme, el escritor bárbaro salía fortalecido de la experiencia y, lo que era verdaderamente importante, salía con una cierta instrucción en el arte de la escritura, una sapiencia adquirida mediante la «cercanía real», la «asimilación real» (como la llamaba Delorme) de los clásicos, una cercanía corporal que rompía todas las barreras impuestas por la cultura, la academia y la técnica." (Bolaño, 2003: 138-140).

${ }^{5}$ Pierre Pain, el mesmerista que protagoniza Monsieur Pain, siente la misma conmoción que Ángel Ros y que el narrador Bolaño de Estrella distante, cuando identifica, ya en los albores de la revelación crucial de la novela, que el ejercicio literario puede tener cabida hasta en la taquilla de un cine, donde una pelirroja expende sin mucho afán los billetes: “- La película acaba de empezar - murmuró sin mirarme una mujer pelirroja algo entrada en carnes, más o menos de mi edad, que se entretenía en escribir algo en un cuaderno escolar cuya única peculiaridad era el color rosa de las hojas. ¡Versos! ¡Una poetisa! Saqué un billete y entré." (Bolaño, 2007: 116).
} 
impregnaba de olor a formol que nosotros intentábamos vanamente disimular encendiendo un cigarrillo tras otro. (Bolaño, 2003: 20-21).

Nótese cómo el aroma del cigarrillo actúa para disfrazar una inminencia. A pesar de la estrechez del cuarto, el penetrante olor del aldehído fórmico se cuela, provocando una sensación de sofocamiento entre los concurrentes. Es interesante cómo Bolaño maneja este tipo de elementos como adelanto indicial de lo que ocurrirá luego en esos espacios. Se sabe que el formol es utilizado en los hospitales para conservar muestras de tejidos, e incluso para el embalsamamiento de los cadáveres. Además, tiene propiedades anestésicas. Con estos antecedentes, es posible argumentar que ya desde las primeras páginas de Estrella distante, el espacio determina la configuración de la lógica narrativa y de las futuras prácticas estéticas de Wieder, quien conservará los cuerpos de varias de las mujeres asesinadas para retratarlas de cara a una exposición fotográfica, además de ayudar al régimen, con sus exhibiciones de poesía aérea, a mantener en un «letargo» el quehacer político y cultural chileno. Como puede adivinarse, los verdaderamente interesados en el ejercicio literario (O’Ryan, el propio Bolaño, como narrador y personaje en esta novela) huyen hacia las fronteras y siguen desarrollando sus respectivos proyectos artísticos, alejados de un país donde los cuerpos, como en la Facultad de Medicina cercana al taller de Soto, se anestesian o se destazan.

Ahora bien, ya que la escritura se vuelve inestable y móvil en los centros, los ejercicios de lectura y discusión literaria se revelarán, por necesidad o voluntad, en los márgenes. Para varios de sus personajes que circunstancialmente han debido habitar espacios restrictivos o decididamente fronterizos, la lectura tendrá una suerte de aura, de encontrada redención ${ }^{6}$. ¿En qué lugares leen los personajes de Bolaño?, ¿por qué motivos? Enric Rosquelles, uno de los tres monologuistas de La pista de hielo, aprende a leer verdaderamente en el espacio marginal de la cárcel, gracias a los libros que su ex mujer y su amor imposible le hacen llegar:

\footnotetext{
${ }^{6}$ Se recordará la ponderación lectora, muy bartlebyana, que realiza el viejo escritor que le renta las máquinas de escribir a Benno von Archimboldi, en la última parte de 2666: "La lectura es placer y alegría de estar vivo o tristeza de estar vivo y sobre todo conocimiento y preguntas. La escritura, en cambio, suele ser vacío [...]. Llegó el día en que decidí dejar la literatura. La dejé. No hay trauma en este paso sino liberación. Entre nosotros le confesaré que es como dejar de ser virgen. ¡Un alivio, dejar la literatura, es decir dejar de escribir y limitarse a leer!" (Bolaño, 2004b: 983-986). Asimismo, en un artículo recogido en Entre paréntesis llamado «Un escritor en la intimidad», el mismo Bolaño reconoce que lo natural de la literatura es leer, no escribir: "Leer, lo dijo Gil de Biedma, es más natural que escribir. Yo añadiría, pese a la redundancia, que también es mucho más sano, digan lo que digan los oftalmólogos. De hecho, la literatura es una larga lucha de redundancia en redundancia, hasta la redundancia final." (Bolaño, 2004c: 322).
} 
Ambas, Lola y Nuria, me dejaron sendos regalos. El de Lola era un libro de Remo Morán. El de Nuria, el libro por excelencia del patinaje, Santa Lydwina y la Sutileza del Hielo, de Henri Lefebvre, en edición francesa de Luna Park, Bruselas. Tanto para el hospitalizado como para el encarcelado no hay mayor presente que un libro. El tiempo es lo único que me sobra, aunque mi abogado dice que pronto estaré en la calle. (Bolaño, 2004a: 167).

Es curioso cómo hasta el intelectualismo más elevado, representado por la figura de Henri Lefebvre (un referente crucial, luego, para el cuento «El viaje de Álvaro Rousselot», de El gaucho insufrible), puede aparecer en estos espacios marginales. Para varios de sus protagonistas, aquel acercamiento tan estrecho a lecturas complejas los desplaza desde aquel estado de adversidad hacia un estado de redención ${ }^{7}$. Si el ejercicio de la lectura ayudaba a Rosquelles a esperar en su celda la definitiva liberación, al joven B del cuento «Últimos atardeceres en la Tierra», el contacto con los libros le permitirá continuar anclado a sus intereses de formación en un ambiente que, aunque no expresamente hostil, se percibe como cambiante y perturbador:

Antes de llegar a Acapulco el padre de B detiene el coche delante de un tenderete de la carretera. En el tenderete ofrecen iguanas. ¿Las probamos?, dice el padre de B. Las iguanas están vivas y apenas se mueven cuando el padre de B se acerca a mirarlas. B lo observa apoyado en el guardabarros del Mustang. Sin esperar respuesta, el padre de B pide una ración de iguana para él y para su hijo [...]. Entonces B desvía la mirada y vuelve a su libro, que permanece abierto sobre la mesa. Es un libro de poesía. Una antología de surrealistas franceses traducida al español por Aldo Pellegrini, surrealista argentino. Desde hace dos días B está leyendo este libro. Le gusta. Le gustan las fotos de los poetas. La foto de Unik, la de Desnos, la de Artaud, la de Crevel. El libro es voluminoso y está forrado con un plástico transparente. No es B quien lo ha forrado (B nunca forra sus libros) sino un amigo particularmente puntilloso. Así que B desvía la mirada, abre su libro al azar y encuentra a Gui Rosey, la foto de Gui Rosey, sus poemas, y cuando vuelve a levantar la mirada la cabeza de su padre ya no está. (Bolaño, 2001: 38-39).

\footnotetext{
${ }^{7}$ Bastará citar a Florita Almada, la vidente de "La parte de los crímenes" de 2666, que en medio de sus espacios de recreación mediados por el esoterismo, aprende a leer y a escribir y se convierte en una lectora omnívora, como Barry Seaman o los hermanos del relato "Músculos", en El secreto del mal: «Así es la vida, justo cuando ella creía que se desvanecían para siempre las posibilidades de estudiar o de retomar los estudios (vana esperanza, en Villa Pesqueira creían que Escuela Nocturna era el nombre de un burdel en las afueras de San José de Pimas), aprendió, sin grandes esfuerzos, a leer y a escribir. A partir de ese momento leyó todo lo que caía en sus manos. En un cuaderno anotó las impresiones y pensamientos que le produjeron sus lecturas. Leyó revistas y periódicos nuevos, leyó los pocos libros que pudo encontrar y su marido, después de cada ausencia traficando con animales en los pueblos vecinos, se acostumbró a traerle libros que en ocasiones compraba no por unidad sino por peso. Cinco kilos de libros. Diez kilos de libros. Una vez llegó con veinte kilos. Y ella no dejó ni uno sin leer y de todos, sin excepción, extrajo alguna enseñanza. A veces leía revistas que llegaban de Ciudad de México, a veces leía libros léperos que la hacían enrojecer, sola, sentada a la mesa, iluminadas las páginas por un quinqué cuya luz parecía bailar o adoptar formas demoniacas, a veces leía libros técnicos sobre el cultivo de viñedos o sobre construcción de casas prefabricadas, a veces leía novelas de terror y de aparecidos, cualquier tipo de lectura que la divina providencia pusiera al alcance de su mano, y de todos ellos aprendió algo, a veces muy poco, pero algo quedaba, como una pepita de oro en una montaña de basura, o para afinar la metáfora, decía Florita, como una muñeca perdida y reencontrada en una montaña de basura desconocida." (Bolaño, 2004b: 539).
} 
La mención, otra vez, a la vanguardia (esta vez por asimilación lectora y no por creación escritural) puede responder a asuntos divergentes. El hecho de haberse detenido en un puesto exótico donde venden carne de iguana, y el creciente interés del joven B por la figura de Gui Rosey, llevan a poner la atención en el movimiento que los personajes realizan de los centros hacia bordes, alteración que modificará significativamente su percepción e identidad.

Es fundamental el aprecio de B por Gui Rosey, un poeta menor que de un momento a otro desaparece del inmediato círculo surrealista, y cuyo paradero, si bien en un comienzo genera intriga, nadie después se anima a descubrir (al igual que Ulises Lima, quien desaparece de la delegación que viaja a Nicaragua en la segunda parte de Los detectives salvajes, y que Henri Simon Leprince, otro poeta menor quien luego de ayudar a los poetas de la resistencia tras la capitulación francesa, durante la Segunda Guerra Mundial, se esconde sin dejar rastro). El viaje que B realiza con su padre desde el DF hasta Acapulco, en el citado cuento del volumen Putas asesinas, conllevará la misma sutil disolución de la identidad del muchacho, que en un principio desea seguir anclado a su pasatiempo lector, pero que, en esos puestos de comida, en los hoteles y luego en los lupanares, va articulando un interés vivo por el paisaje marginal al que accede. En suma, la literatura en los espacios marginales, además de ayudar a desacralizar la práctica literaria, resultará constitutiva como oficio transfigurador para quienes se atreven a asumirla cabalmente ${ }^{8}$.

La literatura, en suma, aparece en las fronteras como una alarma que advierte el desmantelamiento de algún aspecto traído o sostenido desde el centro. No es gratuito, entonces, que los personajes de Bolaño lean hasta en los frentes de batalla, cuando el desmoronamiento de sus tropas y sus líneas de combate sea una inminencia. Es el caso de un oficial del batallón donde lucha el joven Hans Reiter, cuando aún no sueña en convertirse en Benno von Archimboldi. El narrador de 2666 reseña:

Cerca del ordenanza y del oficial que miraba la disposición que el ordenanza daba a las viandas sobre la mesa se encontraba, de espaldas a todos, otro oficial, éste con el uniforme de la Luftwaffe, aburrido de ver pasar a los aviones, que sostenía en una mano un largo cigarrillo y en la otra un libro, una operación sencilla pero que a este oficial de la Luftwaffe parecía costarle ímprobos

\footnotetext{
8 “Creo que todos los escritores, incluso los más mediocres y falsos, los peores escritores del mundo, han sentido durante un segundo la sombra del éxtasis poético. Sin duda, el éxtasis no lo han sentido. El éxtasis, tal cual, quema", sentenciaba Roberto Bolaño en una de las entrevistas más polémicas emitidas por la televisión de Chile. "El éxtasis es terrible, es abrir los ojos en algo difícil de nombrar y soportar [...]. Rimbaud y Lautréamont representan a los poetas adolescentes absolutos, en donde la pureza es tal que quien se atreva a tocarlos, pero a tocarlos de verdad, se quema." (Bolaño en Warnken, 1999).
} 
esfuerzos pues la brisa que soplaba sobre la loma en donde estaban todos le levantaba constantemente las hojas del libro, impidiéndole la lectura, lo que llevaba al oficial de la Luftwaffe a utilizar la mano que sostenía el largo cigarrillo para mantener fijas (o inmóviles o quietas) las hojas del libro levantadas por la brisa, cosa que no conseguía sino empeorar la situación pues el cigarrillo o la brasa del cigarrillo tendía indefectiblemente a quemar las hojas del libro o la brisa desparramaba sobre las hojas le ceniza del cigarrillo, lo que molestaba mucho al oficial, que entonces inclinaba la cabeza y soplaba, con mucho cuidado, pues se encontraba de cara al viento y al soplar la ceniza corría el riesgo de que ésta terminara alojada en sus ojos. (Bolaño, 2004b: 838)

Como en los casos anteriores, la lectura en sitios que no son los habituales es asumida como un aliciente y un mecanismo tenue para que los personajes vayan accediendo, dócilmente, a las zonas marginales de diseminación. En este caso, lo volátil, pero al mismo tiempo lo peligroso de las cenizas del cigarrillo permiten aventurar el inicio de las peripecias del batallón de Reiter, una unidad que se caracterizará por su mutabilidad y contingencia. En el futuro, la tropa tendrá numerosas bajas y transformaciones. Finalmente, en el frente rumano, las cenizas se alojarán irremediablemente en los ojos de los oficiales. Pero gracias a la lectura de los papeles de un tal Boris Abramovich Ansky (unos cuadernos rescatados en las ruinas de una aldea enemiga), Hans Reiter se movilizará, otra vez, hacia espacios fronterizos.

El cuento «Músculos», de El secreto del mal, responde a las mismas lógicas. Este relato, antecedente o ampliación de Una novelita lumpen (2002), presenta a Marta y Enric, dos huérfanos que, como sus equivalentes de la novela citada, comparten las labores de la casa y la afición por los programas de televisión. Enric es un mecánico decidido a destacarse en el fisicoculturismo. Marta trabaja como peluquera y es la narradora del relato. A pesar de realizar actividades que, se supondría, son incompatibles con los altos debates intelectuales, por las mañanas los hermanos comentan anticanónicamente sus lecturas de filosofía antigua. Es importante subrayar cómo varios de los sistemas filosóficos tienen correlato en la cultura de masas, otra de las estrategias textuales de Bolaño que articularía su incordio hacia el canon literario institucionalizado:

Generalmente hablábamos de los filósofos presocráticos a la hora del desayuno. A él el que más le gustaba era Empédocles. Este Empédocles, afirmaba, es como Spiderman. A mí, Heráclito. No sé por qué casi nunca hablábamos de filósofos por la noche. Debía de ser porque por la noche teníamos muchas más cosas de las que hablar o porque a veces llegábamos demasiado cansados de nuestros respectivos trabajos y hablar de filosofía requiere una mente fresca [...]. Sobre esa mesa mi hermano extendía el fascículo de algún presocrático (su obra completa) o alguna revista 
y mientras con la mano derecha manejaba la cuchara o el tenedor, con la izquierda daba vueltas a las páginas.

- Mira lo que pensaba el cabrón de Diógenes de Apolonia.

Yo me quedaba callada y aguardaba sus palabras intentando componer una expresión atenta.

— “Al comenzar un tema cualquiera me parece que es necesario ofrecer un principio indiscutible y una forma de expresión sencilla y decorosa." Ni más ni menos.

- Suena razonable

— Joder si es razonable. (Bolaño, 2007b: 129, 130-131).

Las formas «sencillas» y «decorosas» de expresión están vehiculizadas a través de soportes no tradicionales para quien decide acercarse, con esa solemnidad que a Bolaño le parecía no sólo absurda sino canallesca, a la filosofía. El fascículo o la revista, publicaciones relegadas a la mera difusión e incluso al aligeramiento de las ideas, trastocan al libro en su condición de univocidad para sostener la importancia de las propuestas filosóficas. La elección de un formato "menor" (como anteriormente el interés de B por poetas "menores") responde a una ideología lectora, anticanónica, irrespetuosa, marginal; todos ellos elementos nucleares del ideario estético de Bolaño 9 .

\section{Lectura diseminadora: la apertura del relato}

Literatura presente en cárceles. Literatura presente en los frentes de batalla, en puestos de comida exótica, en las peluquerías, en las playas y en los talleres mecánicos... Tal vez el caso más emblemático del procedimiento lector en la narrativa de Bolaño, atendiendo a la estrategia de desplazamiento desde los espacios céntricos hacia los marginales (donde los últimos asomos de "verdad" han ido a parar), sea el del farmacéutico amigo del profesor chileno Óscar Amalfitano, en 2666. Cuando Rosa aún vivía con Amalfitano en Barcelona, antes de marcharse a San Sebastián en búsqueda del poeta homosexual, cerca de su casa había una farmacia. Mientras estaba de turno, la atendía un joven muy delgado de grandes gafas (¿Belano?), quien pernoctaba teniendo constantemente un libro en las manos. Una noche, Amalfitano se atrevió a preguntarle por sus preferencias literarias. Su respuesta representa uno de los momentos más luminosos de toda la narrativa de Bolaño:

\footnotetext{
${ }^{9}$ La actitud poco reverencial hacia la misma antigüedad griega se visualiza en otro momento de "Músculos", cuando Enric, el hermano, aparece en casa con dos latinoamericanos. Marta se molesta un tanto y se retira a su habitación a leer ni más ni menos que al fundador de la escuela eleática, uno de los oponentes de la visión multi-divínica descrita por Homero y Hesíodo: Jenófanes de Colofón, otro desacralizador: "Terminé de cenar antes que ellos y me encerré en mi habitación [...]. No tenía sueño. Me saqué los zapatos y me tiré en la cama, vestida, con la obra completa de Jenófanes de Colofón ("de la tierra nace todo y en tierra todo acaba"), hasta que los oí levantarse de la mesa.” (Bolaño, 2007b: 139).
} 
Escogía La metamorfosis en lugar de El proceso, escogía Bartleby en lugar de Moby Dick, escogía Un corazón simple en lugar de Bouvard y Pécuchet, y Un cuento de Navidad en lugar de Historia de dos ciudades o El Club Pickwick. Qué triste paradoja, pensó Amalfitano. Ya ni los farmacéuticos ilustrados se atreven con las grandes obras, imperfectas, torrenciales, las que abren caminos a lo desconocido. Escogen los ejercicios perfectos de los grandes maestros. O lo que es lo mismo: quieren ver a los grandes maestros en sesiones de esgrima de entrenamiento, pero no quieren saber nada de los combates de verdad, en donde los grandes maestros luchan contra aquello, ese aquello que nos atemoriza a todos, ese aquello que acoquina y encacha, y hay sangre y heridas mortales y fetidez. (Bolaño, 2004b: 289-290).

Ante todo, es importante señalar que esta cita opera dentro del texto como una reflexión y casi una justificación paradójica del libro mismo (2666). En sus últimos años, Roberto Bolaño tendió a provocar un debate, tanto referencial como teórico, en torno a la novela como género acumulativo y torrencial, en contraposición al cuento. En su afán de seguir abriendo los límites establecidos, el escritor esbozó en varios momentos de su ideario literario la noción de la novela como pura y peligrosa fluidez, y del cuento como un atractivo y necesario ejercicio técnico. En "Consejos sobre el arte de escribir cuentos", incluido en Entre paréntesis, dejó dicho:

Voy a dar algunos consejos sobre el arte de escribir cuentos. Nunca aborde los cuentos de uno en uno. Si uno aborda los cuentos de uno en uno, honestamente, uno puede estar escribiendo el mismo cuento hasta el día de su muerte [...]. Lo mejor es escribir los cuentos de tres en tres, o de cinco en cinco. Si se ve con la energía suficiente, escríbalos de nueve en nueve o de quince en quince. (Bolaño, 2004c: 324).

Esta propuesta revela la agudeza con que el autor asume el género de la narrativa breve, plausible de detenerse al alcanzar un determinado número de páginas o de cuantificarse para, en sintonía con otros relatos, incluirse en un volumen. Son las "sesiones de esgrima de entrenamiento", los momentos en los que el "riesgo" (un riesgo estético y ético a la vez) se ve disminuido. "Los riesgos, en literatura, son de orden ético, básicamente ético, pero no pueden expresarse si no se asume un riesgo formal", comentará luego en una entrevista. "De hecho, en todos los ámbitos de la vida la ética no puede expresarse sin la asunción previa de un riesgo formal.” (Bolaño en Braithwaite: 77). De esta manera, el escritor parece vislumbrar el potencial aún en ciernes de la novela en contraposición con el cuento, limitado como género abarcador debido a sus económicas posibilidades de creación y al estudio academicista y estético dominante (bastará recordar la tradicional separación, elemental, como de taller literario, entre el cuento cortazariano, cerrado, redondo, y el cuento chejoviano, abierto, interrumpido). La novela, entonces, como escenario de combate, como peligroso juego de apuestas totales, importará a Bolaño tanto en su condición 
de exhibición de temáticas recurrentes como en su exploración o adaptación de formas narrativas novedosas. Las cinco partes de 2666, saturadas de vasos comunicantes, o la polifonía de voces de la segunda parte de Los detectives salvajes, sólo por nombrar sus novelas más "riesgosas", serían buenos ejemplos de lo descrito.

En este sentido, y volviendo al ejemplo del ilustrado farmacéutico de "La parte de Amalfitano", parece sustancial que un lector aficionado, que disfruta de los libros en un espacio no tradicional, se acerque a los “entrenamientos” de los grandes maestros. Los combates descampados, los saltos espectaculares donde por lo general quedan expuestas las fisuras de los recursos narrativos de los grandes escritores, son dejados, paradójicamente, pero sin pena, a condición de que la academia y la crítica los examine sin disfrute. Y por esto, la figura del joven farmacéutico encarna una propuesta lectora interesante, que abarcaría a los demás personajes que asumen dicha actividad con fervor entre sus páginas y que se conecta, en conclusión, con aquello que el postestructuralismo francés piensa en torno a la lectura.

"La avidez misma del conocimiento nos arrastra a sobrevolar o a encabalgar ciertos pasajes (presentados como 'aburridos') para reencontrar lo más rápidamente posible los lugares quemantes de la anécdota" (Barthes, 2007: 20), afirmaba Roland Barthes en El placer del texto. Según la lección que otorgara el crítico francés, el placer lector parece estar reñido con la edificación de una metodología de lectura en un espacio pretendidamente céntrico, que anquilosa y reverencia a autores eximios y a sus predicados, las obras maestras. Cabe la posibilidad de que, en su posición limítrofe, el acto de destacar una obra y en suma fijarla para la posteridad sea para el farmacéutico una opción aún más peligrosa que la contracultura. En palabras de Barthes: "Ni la cultura ni su destrucción son eróticos: es la fisura entre una y otra la que se vuelve erótica [...]. Texto de placer: el que contenta, colma, da euforia; proviene de la cultura, no rompe con ella y está ligado a una práctica confortable de la lectura" (15-25). Por eso, sin objetar ni preferir espacio alguno, la mayoría de los personajes de Bolaño está constantemente leyendo al descubrir, y actualizar en dicha actividad, el ideario primero del postestructuralismo en torno a esta actividad:

La lectura (ese texto que escribimos en nuestro propio interior cuando leemos) dispersa, disemina; o, al menos, ante una historia [...], vemos perfectamente que una determinada obligación de seguir un camino (el «suspenso») lucha sin tregua dentro de nosotros contra la fuerza explosiva del texto, su energía digresiva: con la lógica de la razón (que hace legible la historia) se entremezcla una lógica del símbolo. Esta lógica no es deductiva, sino asociativa: asocia al texto material (a cada una de sus frases) otras ideas, otras imágenes, otras significaciones. (Barthes 1987: 35-37). 
Se señalaba en un comienzo: no todos los personajes de Bolaño escriben; pero, sin duda, todos leen. El acceso, de modo febril, casi obsesivo, a la literatura en espacios como bares periféricos, cárceles o farmacias, supondría, por estas razones, el siguiente eslabón luego de que sus personajes que escriben dejan de hacerlo.

Referencias bibliográficas

Barthes, Roland, El susurro del lenguaje: Más allá de la palabra y de la escritura (trad. C. Fernandez Medrano). Barcelona: Paidós, 1987. , El placer del texto (trad. Nicolás Rosa). México: Siglo XXI, 16 ${ }^{\mathrm{a}}, 2007$.

Bolaño, Roberto, García Porta, Antoni, Consejos de un discípulo de Morrison a un fanático de Joyce. Barcelona: Acantilado, 2006.

Bolaño, Roberto, Putas asesinas. Barcelona: Anagrama, 2001. , Estrella distante. Barcelona: Compactos Anagrama, 2a edición, 2003. , La pista de hielo. Barcelona: Seix Barral, 2004a. , 2666. Barcelona: Anagrama, 2004b. , Entre paréntesis. Barcelona: Anagrama, 2004c. , Los detectives salvajes. Barcelona: Compactos Anagrama, $7^{\text {a }}$ edición, 2005. , Monsieur Pain. Barcelona: Anagrama, $2^{\mathrm{a}}$ edición, 2007a. , El secreto del mal. Barcelona: Anagrama, 2007b. , El Tercer Reich. Barcelona: Anagrama, 2010.

Braithwaite, Andrés (comp.), Bolaño por sí mismo. Entrevistas escogidas. Santiago de Chile: Ediciones Universidad Diego Portales, 2002.

Del Pozo, Alberto, «Lo "literario” como problema en la obra y la crítica sobre Roberto Bolaño: notas para un debate», en A contracorriente. Revista de historia social y literatura de América Latina. North Carolina State University: Department of Foreign Languages and Literatures, volumen 11, n 2, 2014, pp. 195-220.

Espinosa, Patricia (comp.), Territorios en fuga: Estudios críticos sobre la obra de Roberto Bolaño. Santiago de Chile: Frasis, 2003.

Manzoni, Celina (comp.), Roberto Bolaño. La escritura como tauromaquia. Buenos Aires: Corregidor, 2002.

Pauls, Alan (2008), «La solución Bolaño», en Paz Soldán, Edmundo, Faverón Patriau, Gustavo (eds.), Bolaño salvaje. Barcelona: Candaya, 2008, pp. 319-332.

Poblete Alday, Patricia, Roberto Bolaño: Otra vuelta de tuerca. Santiago de Chile: Universidad Academia de Humanismo Cristiano, 2010. 
Ríos Baeza, Felipe, Roberto Bolaño: Una narrativa en el margen. Desestabilizaciones en el canon y la cultura. Valencia: Tirant Lo Blanch, 2013.

Solotorevsky, Myrna. El espesor escritural en novelas de Roberto Bolaño. Rockville (EU): Hispamérica, 2012.

Warnken, Cristián (1999) «Entrevista con Roberto Bolaño». La belleza de pensar. Canal 13 Cable. Televisión. [60 minutos]. 